\title{
THE SPIDER GENUS STYPOSIS (ARANEAE, THERIDIIDAE) $^{1}$
}

\author{
By Herbert W. Levi \\ Museum of Comparative Zoology, Harvard University
}

Theridiid spiders usually have eight eyes. Only recently the genus Archerius Levi (1957, Trans. Amer. Micros. Soc., 76: II4) was described from some California specimens having only six eyes. Since then an eight-eyed species from Japan was seen, a species having the anterior median eyes small. The number of eyes, then, may not be of generic importance.

Since the work on Archerius, another theridiid genus has been found in which the eye number is variable. In some species the anterior median eyes are present but small; other species lack them entirely. Judging by their similar appearance and by the genital structure, the species are closely related and belong to the genus Styposis.

A grant from the National Institutes of Health (E-I944) and a National Science Foundation grant (G-43I7) made the completion of this paper possible. I would like to thank Dr. W. J. Gertsch and Dr. A. M. Chickering for specimens used and Professor M. Vachon for permitting me to examine $S$. flavescens in the Muséum National d'Histoire Naturelle in Paris.

\section{Styposis Simon}

Styposis Simon, 1894, Histoire Naturelle des Araignées, 1:592. Type species by original designation and monotypy: $S$. flavescens Simon.

Small unpigmented spiders, less than $2 \mathrm{~mm}$. total length. In some species carapace almost circular, weakly sclerotized, with six large eyes (except all eyes relatively small in $S$. ajo, Figure 27) arranged in two groups of three eyes touching each other (Figs. I, 5, IO, II). In other species ( $S$. flavescens, $S$. scleropsis) carapace longer than wide, sclerotized, with raised reticulate pattern (Figs. I8, 24). In all species anterior median eyes absent or minute, their maximum diameter equal to radius of posterior medians. Chelicerae weak with one or two teeth on anterior margin (Fig I I), probably none on posterior. Legs fairly long; in some species patella and tibia 2.7 times carapace length (S. clausis), in others shorter I.4 times carapace length ( $S$. ajo, $S$. flavescens). Legs with many setae; comb on fourth tarsus greatly reduced, its setae almost smooth. Abdomen soft, sometimes wider than long, or high. Colulus two minute hairs slightly anterior of

\footnotetext{
${ }^{1}$ Published with the aid of a grant from the Museum of Comparative Zoology at Harvard College.
} 
usual position, difficult to discern and could not be found in some species.

Female genitalia with two seminal receptacles. Male palpus weakly sclerotized, parts translucent and difficult to delineate. Bulb twisted so that embolus faces the outside (and is partly hidden by the cymbium), and median apophysis faces ventrally (Figs. 6, 9, I6, I9). Median apophysis ( $\mathrm{M}$ in Figs. 8, I4, I 5, 20) a very large structure, functional, its end lying against the paracymbial hook (Fig. I4) at the distal end of the cymbium. Radix (R) present. The large structure supporting the embolus in $S$. chickeringi and $S$. flavescens probably is the radix ( $\mathrm{R}$ in Figs. I4, I 5, 2O).

Six species are known from Central America and northern South America and one from the southwestern United States.

Styposis differs from Archerius by lacking the large colulus and by being less sclerotized. It differs from Sphyrotinus by having the anterior median eyes reduced in size or absent and by the unusual position of the bulb in the palpal cymbium.

\section{Styposis flavescens Simon \\ Figures 7, I 8-22}

Styposis flavescens Simon, 1894, Histoire Naturelle des Araignées, 1:592. Fig. 599. O type from Venezuela, in the Muséum National d'Histoire Naturelle, Paris, examined.

Description. Carapace, sternum brown. Legs light brown. Abdomen whitish, without pigment. Carapace longer than wide. Cephalothorax heavily sclerotized; carapace and sternum with a net-like sclerotized pattern (Fig. I8). Diameter of anterior median eyes about equal to the radius of posterior medians. Anterior median eyes their radius apart, their radius from laterals. Posterior median eyes one-third diameter apart, two-thirds from laterals. Abdomen suboval in shape. Total length of female $\mathrm{I} .4 \mathrm{~mm}$. Carapace, 0.68 $\mathrm{mm}$. long, $0.53 \mathrm{~mm}$ wide. First femur, $0.89 \mathrm{~mm}$.; patella and tibia, $0.92 \mathrm{~mm}$.; metatarsus $0.62 \mathrm{~mm}$; tarsus, $0.4 \mathrm{I} \mathrm{mm}$. Second patella and tibia, $0.68 \mathrm{~mm}$.; third, $0.47 \mathrm{~mm}$.; fourth, $0.68 \mathrm{~mm}$. Total length of male $1.5 \mathrm{~mm}$. Carapace $0.75 \mathrm{~mm}$. long, $0.56 \mathrm{~mm}$. wide. First femur, I.04 mm.; patella and tibia, $1.22 \mathrm{~mm}$.; metatarsus, $0.8 \mathrm{I} \mathrm{mm}$.; tarsus, $0.47 \mathrm{~mm}$. Second patella and tibia, $0.83 \mathrm{~mm}$; third, $0.59 \mathrm{~mm}$.; fourth, $0.70 \mathrm{~mm}$. The epigynum (Figs. 7, 22) has a slight median projection. The palpus (Figs. I9, 20) has a median apophysis with two projecting prongs, easily seen in lateral view. (Fig. 7 was made from the type, Figs. I 8-22 from specimens collected in Nicaragua). 
Record. Nicaragua. Musawas, Waspuc River, Oct. IO-31, 1955, 우, ơ , Nov. I-4, 1955, ㅇ, ơ (B. Malkin).

\section{Styposis chickeringi, new species}

Figures IO-I 7

Types. Male holotype and female paratypes from El Valle, Panama, July I936 (A. M. Chickering), in the Museum of Comparative Zoology.

Description. Spider colorless, except for silvery eyes and spots of pigment where anterior median eyes usually are. Posterior median eyes one diameter apart, touching laterals. Chelicerae with one blunt tooth (Fig. II). Abdomen wider than long (Fig. IO). Measurements of male holotype, total length $\mathrm{I} .3 \mathrm{~mm}$. Carapace, $0.77 \mathrm{~mm}$. long, $0.72 \mathrm{~mm}$. wide. First femur, $1.50 \mathrm{~mm}$.; patella and tibia, 1.82 mm.; metatarsus, I. $32 \mathrm{~mm}$.; tarsus, $0.44 \mathrm{~mm}$. Second patella and tibia, I. $22 \mathrm{~mm}$.; third, $0.75 \mathrm{~mm}$.; fourth, $0.96 \mathrm{~mm}$. Measurements of female paratype, total length $\mathrm{I} .3 \mathrm{~mm}$. Carapace, $0.60 \mathrm{~mm}$. long, $0.55 \mathrm{~mm}$. wide. First femur, I.25 mm.; patella and tibia, $1.35 \mathrm{~mm}$.; metatarsus, $0.96 \mathrm{~mm}$. ; tarsus, $0.36 \mathrm{~mm}$. Second patella and tibia, 0.88 $\mathrm{mm}$. ; third, $0.52 \mathrm{~mm}$.; fourth, $0.82 \mathrm{~mm}$.

Diagnosis. The genitalia (Figs. I2, I3, I6, I7) as well as the eye distance separate this species from the others of this genus.

\section{Styposis nicaraguensis, new species}

Figures 8-9

Type. Male type from Musawas, Waspuc River, Nicaragua, October IO, 3I, I955 (B. Malkin), in the American Museum of Natural History.

Description. Spider slightly yellowish. Anterior median eyes absent. Anterior eyes slightly more than their diameter apart. Posterior median eyes their radius apart, touching laterals. Chelicerae with two teeth on the anterior margin. Total length of male type $1.4 \mathrm{~mm}$. Carapace $0.62 \mathrm{~mm}$. long, $0.55 \mathrm{~mm}$. wide. First femur, $1.46 \mathrm{~mm}$; patella and tibia, $1.55 \mathrm{~mm}$.; metatarsus $1.03 \mathrm{~mm}$.; tarsus, $0.47 \mathrm{~mm}$. Second patella and tibia, r.o mm.; third, $0.56 \mathrm{~mm}$.; fourth, $0.94 \mathrm{~mm}$.

Diagnosis. The male palpus (Fig. 9) distinguishes this species.

\section{Styposis clausis, new species}

Figure I-4

Types. Female holotype, female paratype from Forest Reserve, Canal Zone, July 4-6, 1939 (A. M. Chickering), in the Museum of Comparative Zoology. 

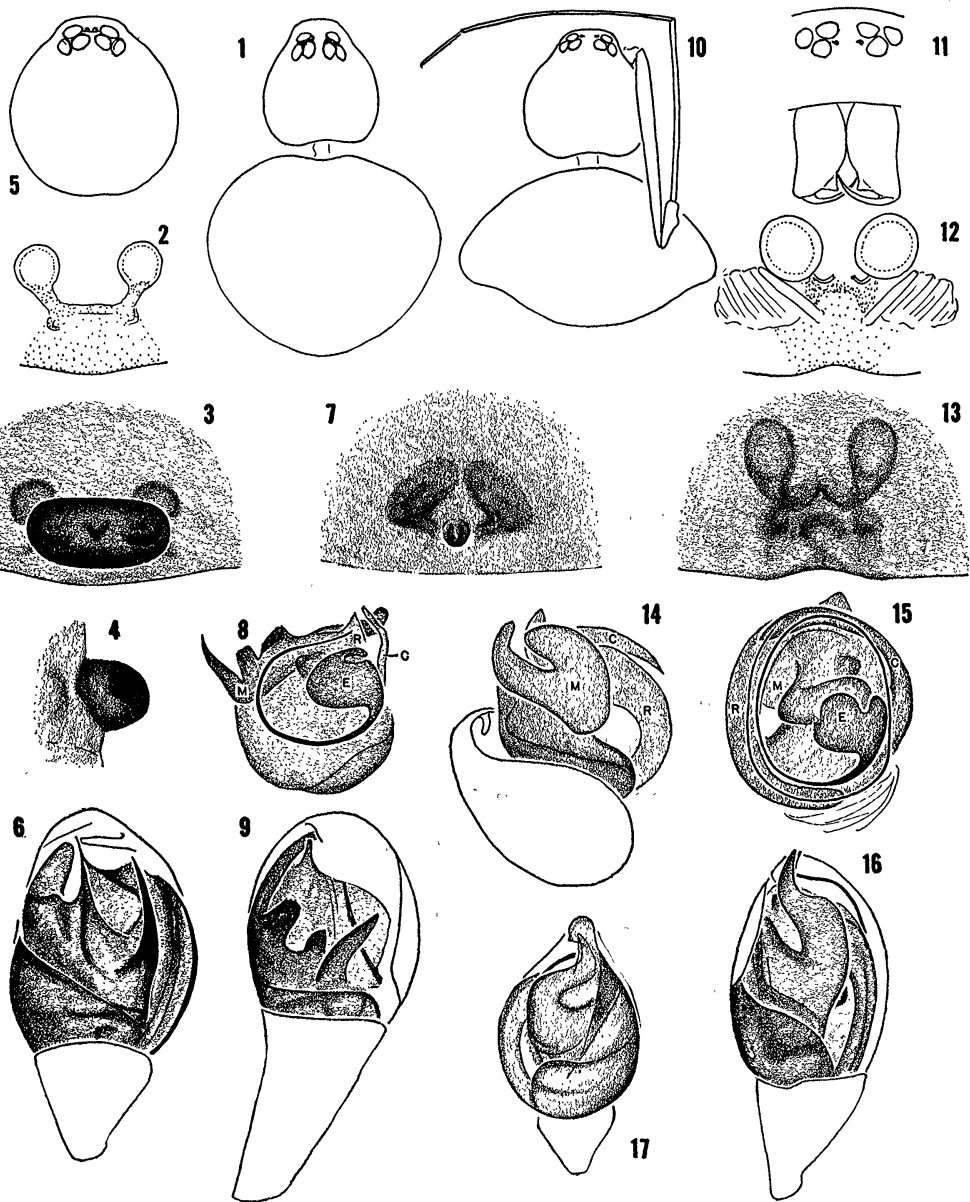

Figs. 1-4. Styposis clausis, new species. 1. Female. 2. Female genitalia, dorsal view. 3. Epigynum. 4. Epigynum from side. Figs. 5-6. S. rancho, new species. 5. Carapace of male. 6. Left palpus. Fig. 7. S. flavescens Simon, epigynum. Figs. 8-9. S. nicaraguensis, new species, palpus. 8. Expanded, ectal view. 9. Ventral view. Figs. 10-17. S. chickeringi, new species. 10. Female. 11. Head of female. 12. Female genitalia, dorsal view. 13. Epigynum. 14. Palpus expanded, subventral view. 15. Palpus expanded, ectal view. 16. Palpus of type. 17. Right palpus of paratype drawn at slightly different angle. 

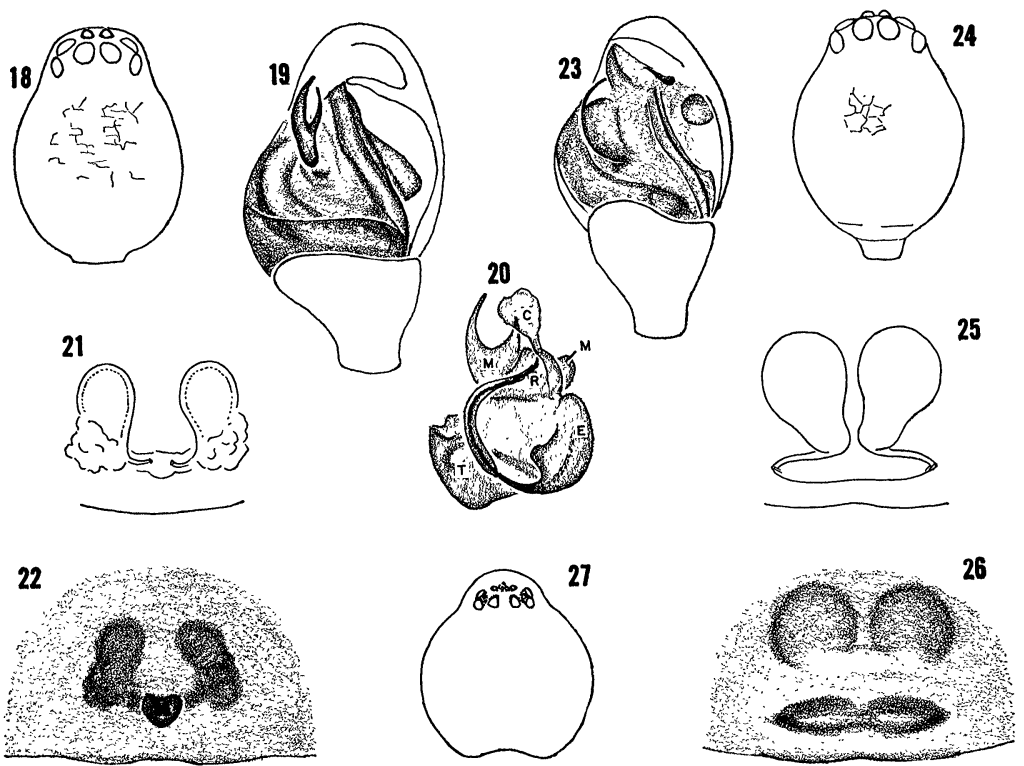

Figs. 18-22. S. flavescens Simon. 18. Carapace of female. 19-20. Left palpus. 19. Ventral view. 20. Ectal view, expanded. 21. Female genitalia, dorsal view. 22. Epigynum. Figs. 23-24. S. scleropsis, new species. 23. Palpus. 24. Carapace of male. Figs. 25-27. S. ajo, new species. 25. Female genitalia, dorsal view. 26. Epigynum. 27. Carapace of female. (Abbreviations: $\mathrm{C}$, conductor; E, embolus; $M$, median apophysis; $R$, radix; $T$, tegulum).

Description. Carapace slightly yellowish, otherwise colorless. Six eyes. Anterior eyes one diameter apart. Posterior median eyes onethird diameter apart, almost touching laterals. Chelicerae with one blunt tooth on anterior margin. Abdomen wider than long when filled with eggs, otherwise longer than wide. It is not known whether the structure on the epigynum (Figs. 3, 4) is an epigynal plug or part of the epigynum. As the structures of the two specimens examined differ slightly, it probably is an epigynal plug. Total length $1.7 \mathrm{~mm}$. Carapace, $0.73 \mathrm{~mm}$. long, $0.69 \mathrm{~mm}$. wide. First femur, $1.72 \mathrm{~mm}$.; patella and tibia, I.95 mm.; metatarsus, I. $33 \mathrm{~mm}$.; tarsus, $0.52 \mathrm{~mm}$. Second patella and tibia, 1.1 $4 \mathrm{~mm}$; third, $0.73 \mathrm{~mm}$.; fourth, $1.06 \mathrm{~mm}$.

Diagnosis. The arrangement of the eyes (Fig. I) and genitalia (Fig. 2) separate this species from others. 


\section{Styposis rancho, new species}

Figures 5-6

Type. Male type from Rancho Grande, Venezuela, December 20, 1954 (A. M. Nadler), in the American Museum of Natural History.

Description. Carapace with a slightly dusky border. Abdomen with some white pigment on dorsum. Anterior median eyes minute. Anterior lateral eyes about one diameter apart. Posterior median eyes one-third of their diameter apart. Chelicerae with one tooth on the anterior margin. Abdomen probably wider than long, damaged in the type specimen. Total length $\mathrm{I} .6 \mathrm{~mm}$. Carapace $0.62 \mathrm{~mm}$. long, $0.54 \mathrm{~mm}$. wide. First femur, $0.96 \mathrm{~mm}$.; patella and tibia, I.02 mm.; metatarsus, $0.75 \mathrm{~mm}$.; tarsus, $0.34 \mathrm{~mm}$. Second patella and tibia, 0.77 $\mathrm{mm}$.; third, $0.45 \mathrm{~mm}$.; fourth, $0.65 \mathrm{~mm}$.

Diagnosis. The eye arrangement (Fig. 5) and the palpus (Fig. 6) separate this species from others.

\section{Styposis scleropsis, new species}

Figures 23, 24

Type. Male from Summit, Panama Canal Zone, August 23-28, I95O (A. M. Chickering), in the Museum of Comparative Zoology.

Description. Carapace, sternum, legs light brown. Abdomen grayish white. Carapace sclerotized, reticulate. Cephalothorax slightly elongated behind (Fig. 24). Anterior median eyes half the diameter of other eyes. Anterior median eyes their radius apart, two-thirds diameter from laterals. Posterior median eyes almost touching, their radius from laterals. Chelicerae heavy with a large tooth far removed from base of fang and a smaller tooth on base of larger one. Abdomen higher than long. Around the spinnerets a very lightly sclerotized ring, hardly different in color from less sclerotized portions. Colulus with two setae quite far anterior. Total length $1.2 \mathrm{~mm}$. Carapace, $0.78 \mathrm{~mm}$. long, $0.52 \mathrm{~mm}$. wide. First femur, I.00 mm.; patella and tibia, I.1 $8 \mathrm{~mm}$.; metatarsus, $0.65 \mathrm{~mm}$.; tarsus, $0.39 \mathrm{~mm}$. Second patella and tibia, $0.76 \mathrm{~mm}$.; third, $0.48 \mathrm{~mm}$.; fourth, $0.66 \mathrm{~mm}$.

Diagnosis. This species resembles Cerocida in the slightly elongated cephalothorax and the high abdomen. However, the small anterior median eyes and the palpal structure place it in Styposis. The shape of the carapace and the transparency of the palpal sclerites (Fig. 23) separate it from other species. 
Styposis ajo, new species

Figures 25-27

Type. Female from 30 miles south of Ajo, Pima County, Arizona, January 4, I94I (S. and D. Mulaik), in the American Museum of Natural History.

Description. Colorless except for pigment around eyes. Diameter of anterior median eyes less than half that of others. Anterior median eyes two and one-half diameters apart, one diameter from laterals. Posterior median eyes one diameter apart, their radius from laterals. Abdomen oval, longer than wide. Total length I. $6 \mathrm{~mm}$. Carapace, $0.60 \mathrm{~mm}$. long, $0.55 \mathrm{~mm}$. wide. First femur, $0.78 \mathrm{~mm}$; ; patella and tibia, $0.88 \mathrm{~mm}$.; metatarsus, $0.62 \mathrm{~mm}$; tarsus, $0.39 \mathrm{~mm}$. Second patella and tibia, $0.67 \mathrm{~mm}$; ; third, $0.52 \mathrm{~mm}$. ; fourth, $0.83 \mathrm{~mm}$.

Diagnosis. This species differs from others by the shape of the epigynum (Fig. 26). It is the only member of the genus from north of Central America. 

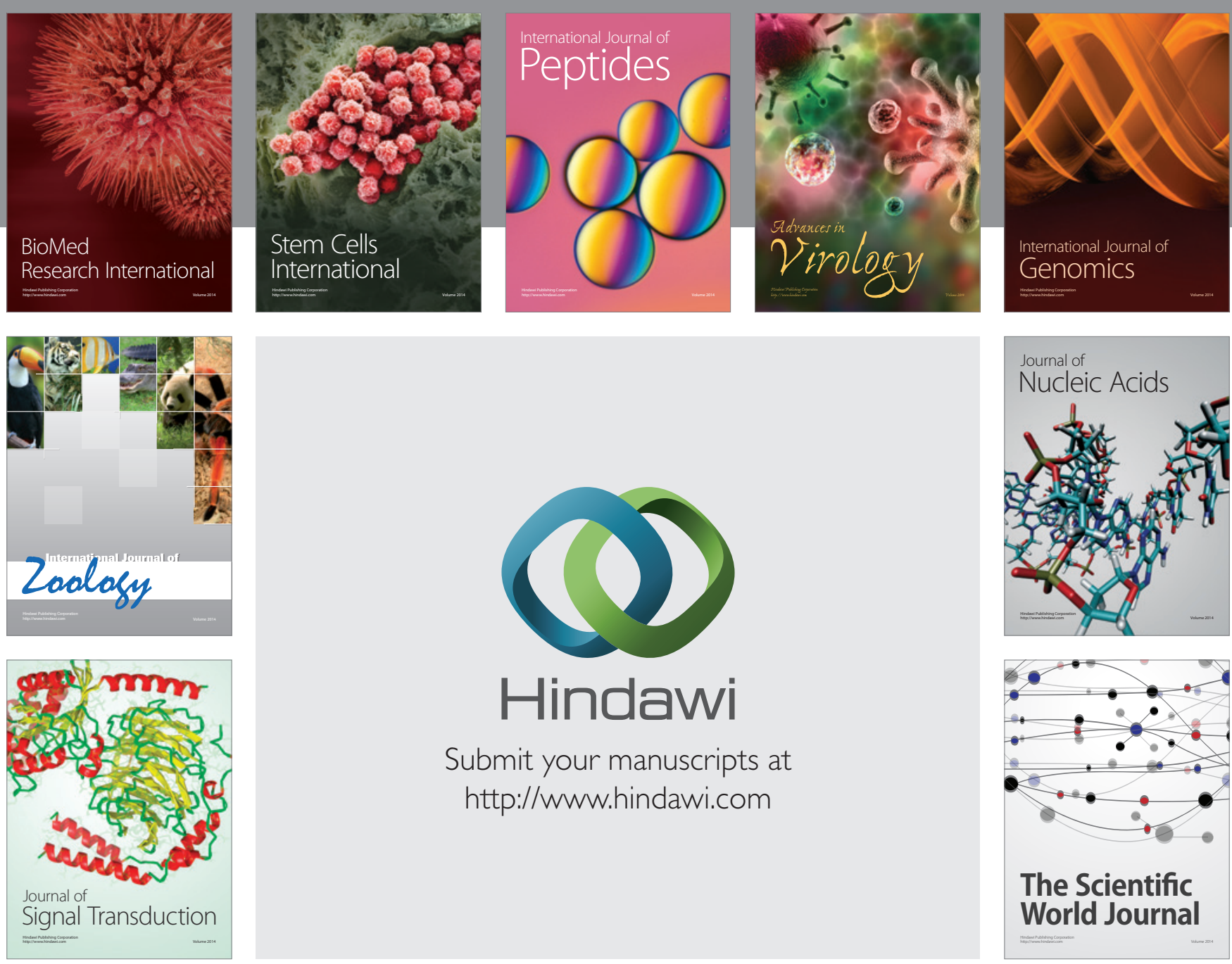

Submit your manuscripts at

http://www.hindawi.com
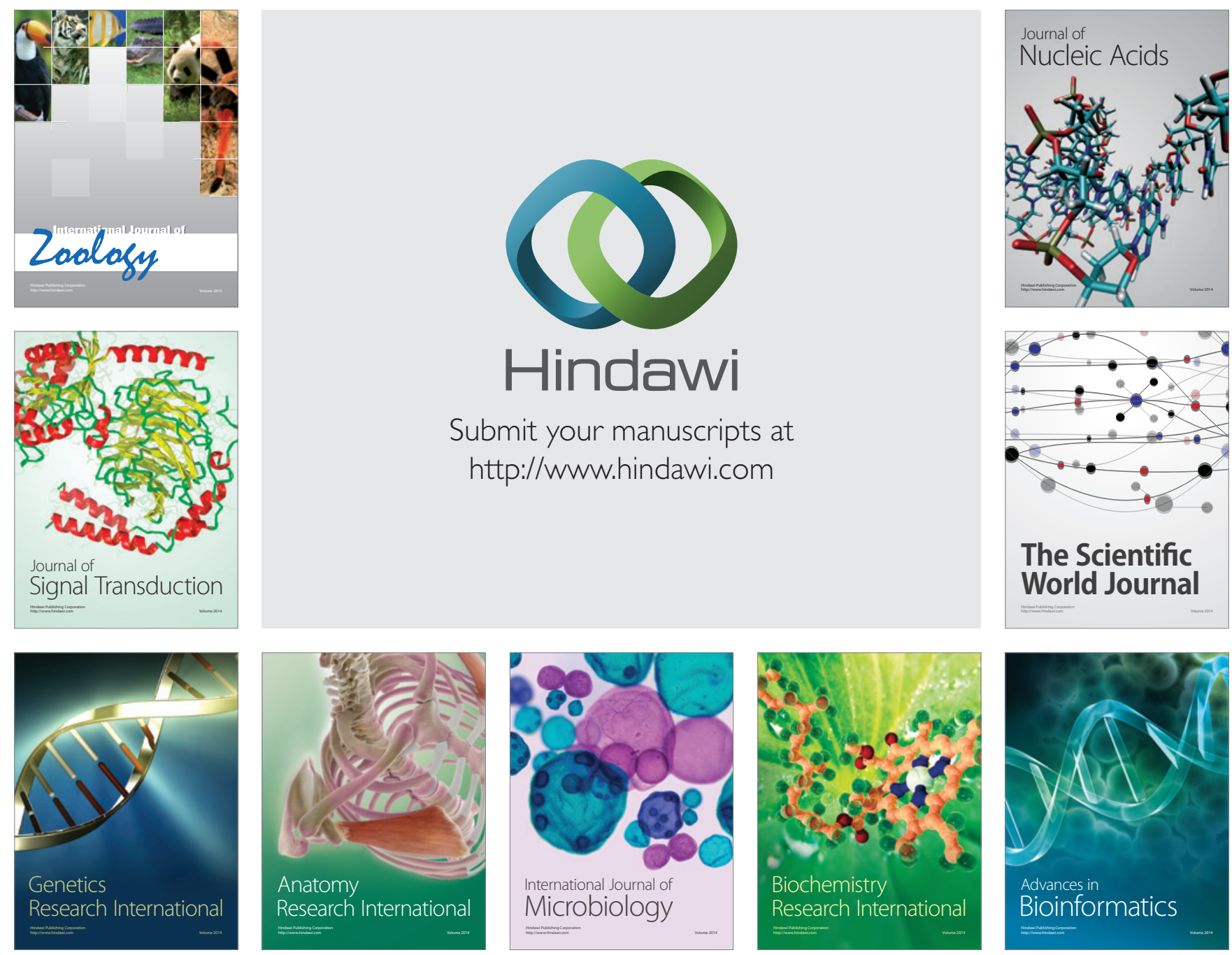

The Scientific World Journal
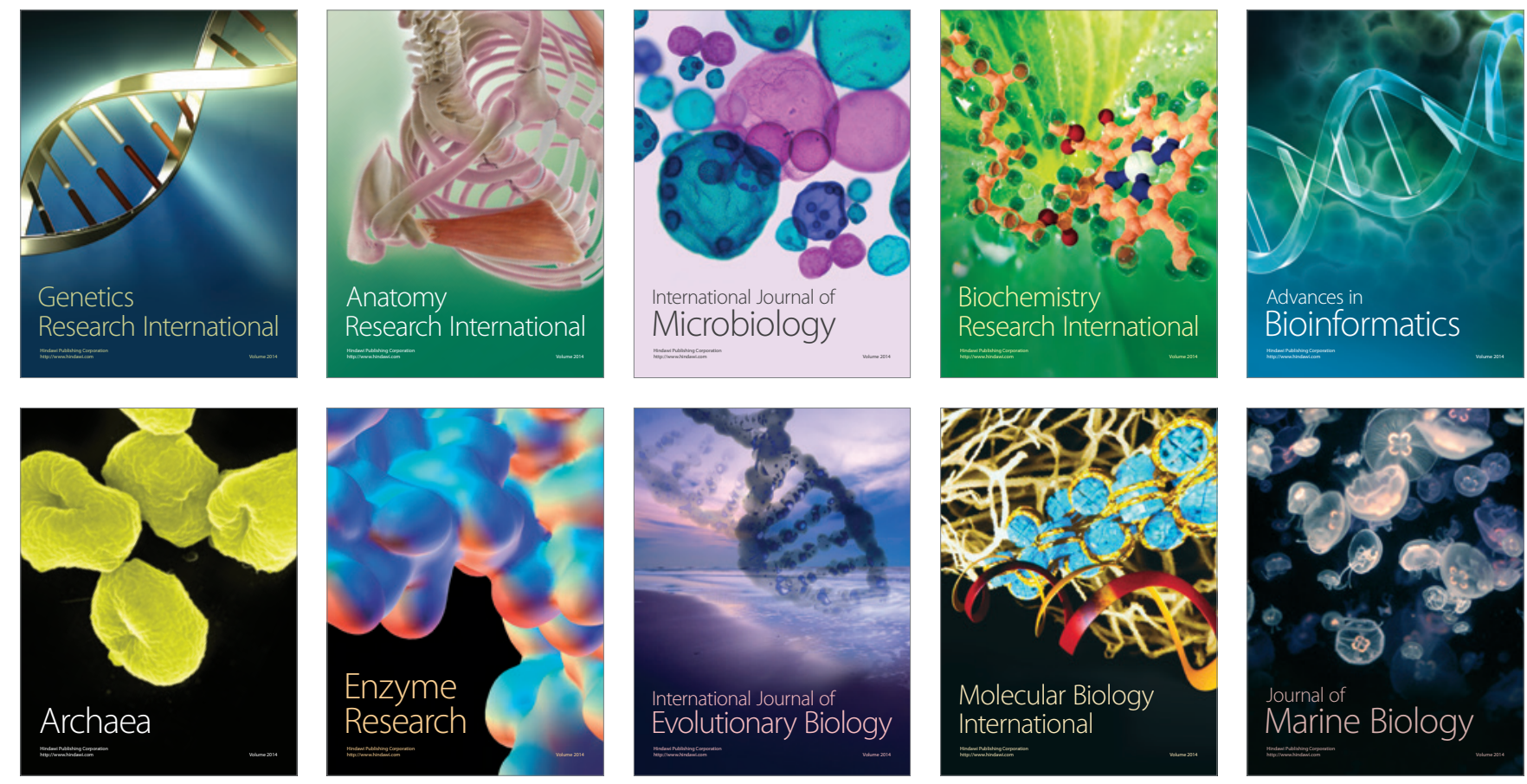